\title{
Determination of Water Samples Contaminated with Oil and Oil Product
}

\author{
E.M.Gadirova, E.G.Azimov, N.Sh.Sharifova \\ Baku State University \\ *Corresponding Author: E.M.Gadirova, Baku State University
}

Received Date: 25-06-2017

Accepted Date: 3-07-2017

Published Date: 07-07-2017

\begin{abstract}
In the viewed article, sea water samples were taken from two district of Absheron peninsula: Guneshli deposit and Hovsan field near the Caspian Sea, their chromatographic analysis and the determination of organic toxic substances were carried out.
\end{abstract}

Keywords: oil, chromatographic analysis, organic substances, water samples and so on.

\section{INTRODUCTION}

Now a days, the demand for oil and oil products lead to extraction, processing, internal and international transformation of oil in much higher quantities. The high consumption of oil and oil products pave the way for importing of carbon dioxide into the atmosphere. Carbon dioxide is one of the main reason of global warming and greenhouse effect. In addition, processing, oil transportation and other related activities cause contamination of ocean, sea, river ecosystems. [1,2]

There are several types of pollution: air pollution, water pollution, soil pollution, and so on. The most essential one is the pollution of water ecosystems. Water pollution occurs as the result of mixing chemical hazardous substances, agricultural waste into the water as well as acquisition of side products during some operations in oil industry, oil spills, ballast water. [3]

In general, the main causes of water pollution with oil and oil products includes arisen leakage during oil extraction process, transportation accidents, unloading of residual oil into the sea and etc. The collapse of oil at tankers is very serious environmental problem. The quantity of oil and oil products merging into water ecosystems contains 12 percent of total oil. As the result, oil wreckages cover the surface of the water as the blanket, so that, prevent animals living there from respiration, as well as hinders development of green plants and photosynthesis process. [4,5]

The main components of oil products includes hydrocarbons. Various organic substances, mainly polycyclic aromatic hydrocarbons are found in the content of oil. It is well known that, aromatic hydrocarbons have toxic properties. Their $1 \%$ concentrationin water is sufficient to destroy the crops. The most dangerous aromatic hydrocarbon is benzene. [5,6]

Heavy fractions of oil is more harmful and cause great harm to creautes. Light fractions are not safe too.They have a negative impact on human health. [7]

The determination of content of water samples contaminated with oil and oil products were carried by researchers. Analysis have been implemented in order to assign organic toxic substances in the content of oil and oil products. That is why, from two district of the Absheron Peninsula: Guneshli deposit and Caspian Sea near the Hovsan water samples were taken. From the analysis of the water samples, their organic content was clarified, chromatographic analysiswere carried out (picture 1). The results are given in Table 1. 
Determination of Water Samples Contaminated with Oil and Oil Product

Table1. Organic subtances in the water samples taken from Guneshli deposit and Hovsan field.

\begin{tabular}{|c|c|c|}
\hline $\begin{array}{c}\text { Polycyclic aromatic } \\
\text { hydrocarbons, } \boldsymbol{\mu g} / \mathbf{l}\end{array}$ & Guneshli deposit & Hovsan \\
\hline Naphthalene & 0,09 & 0,19 \\
\hline Acenaftilen & $<0.01$ & 0.01 \\
\hline Acenaften & 0,01 & 0,07 \\
\hline Fluoren & 0,04 & 0,17 \\
\hline Phenanthrene & 0,09 & 0,01 \\
\hline Anthracene & 0,01 & 0,01 \\
\hline Fluoranten & 0,01 & 0,01 \\
\hline Pyrene & 0,01 & 0,00 \\
\hline Benz(a)anthracene & $<0.01$ & 0,01 \\
\hline Chryzen & 0,02 & 0,03 \\
\hline Benz(b+j+k)fluoranten & 0,01 & 0,01 \\
\hline Benz(a)pyrene & 0,01 & $<0.01$ \\
\hline Inden(1,2,3-cd)pyrene & $<0.01$ & $<0.01$ \\
\hline Benz(ghi)perilen & $<0.01$ & $<0.01$ \\
\hline Dibenz(ah)antracen & $<0.01$ & 0,53 \\
\hline$\sum 16$ Individual PAK & 0,29 & \\
\hline
\end{tabular}

\section{GUNESHLI DEPOSIT}

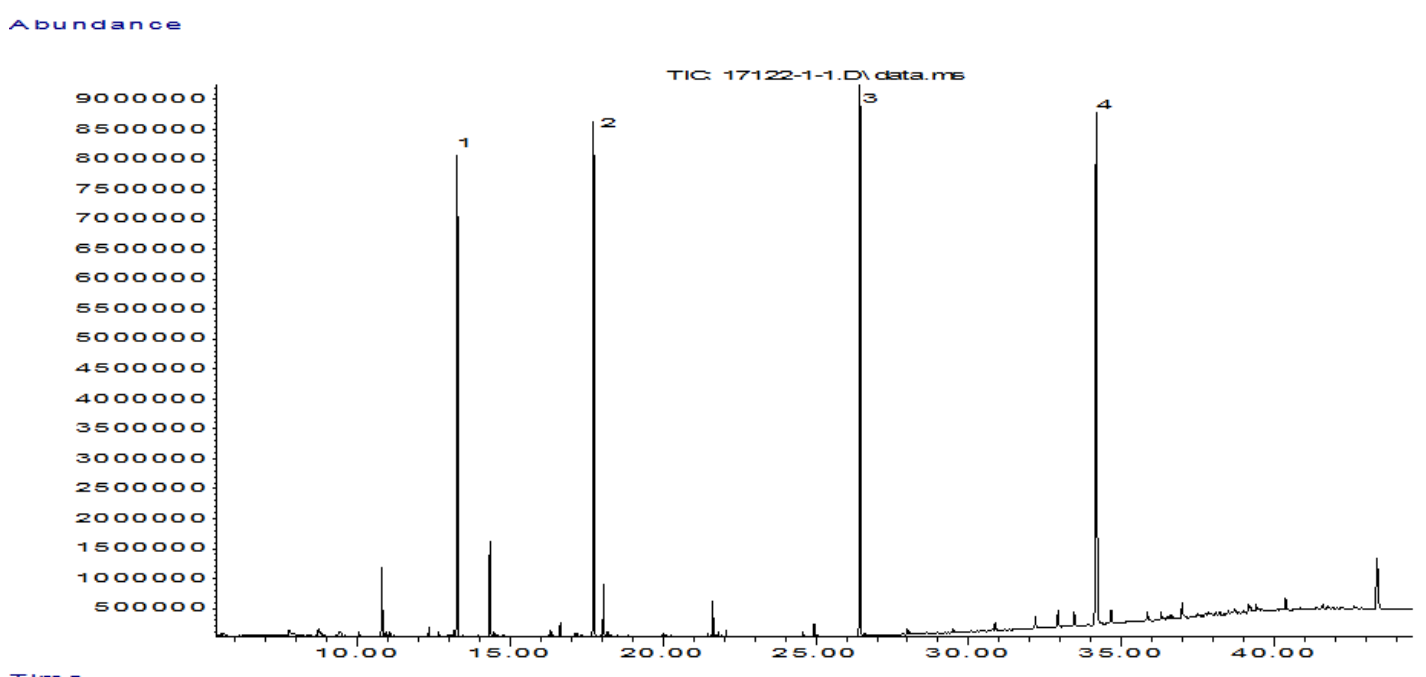

Picture1. Chromatographic analysis of water samples taken from Guneshli deposit and Hovsan field.

\section{HOVSAN FIELD}

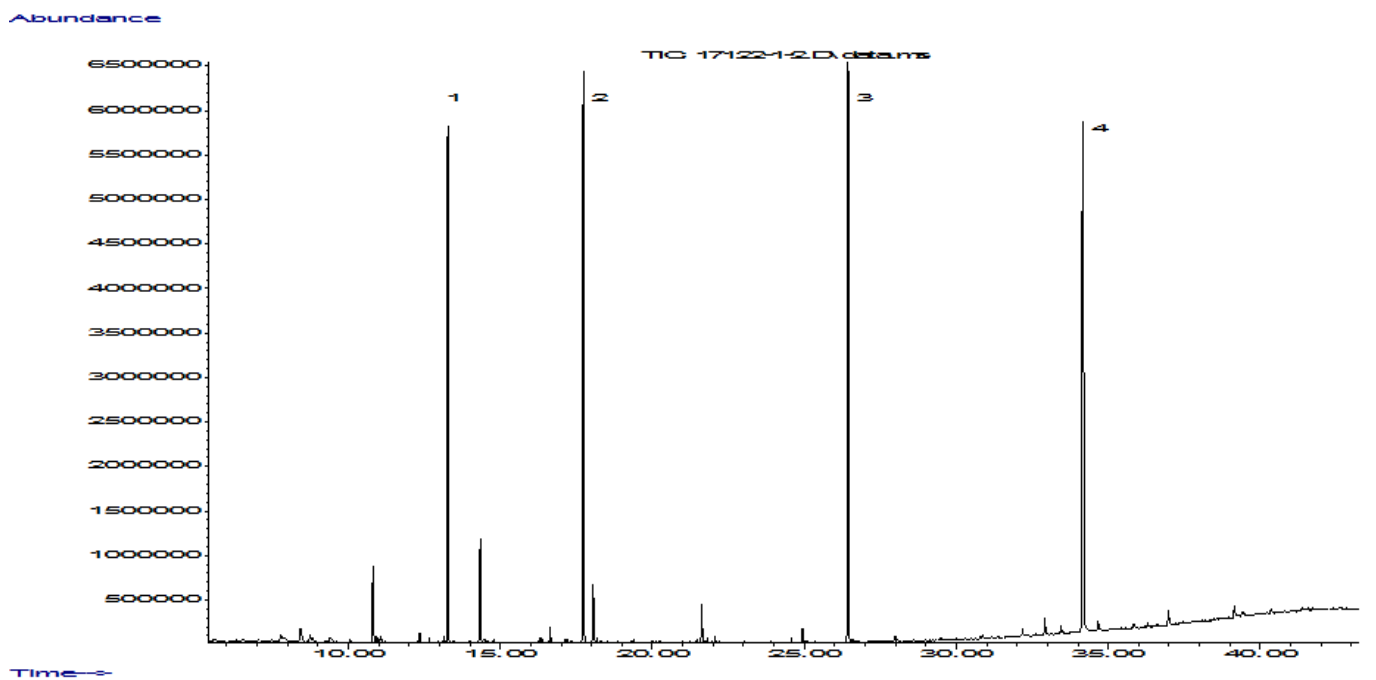

The purpose of the article is that, determination of content of water samples taken from 2 district of Absheron peninsula gave opportunity to assign toxic substances in these water samples. 


\section{LITERATURE}

[1] Budyko Mikhail Ivanovich // Global Ecology M.,1972.-327p.

[2] Problems of ecological safety of water supplysources.-Ecological systems and devices.2006.№5.p.17-20.

[3] The Caspian Sea. State of the Environment // Report of the Provisional Secretariat of the Framework Convention for the Protection of the Marine Environment of the Caspian Sea and the Project Management and Coordination Office of the CASPECO Project, 2011, p. 28.

[4] Stradomskaya AG, Semenov A.D. The level of contamination of water and bottom sediments of shallow sections of the Caspian Sea by oil products and the main ways of their receipt// Conf. On fish-toxictoxicology. T.2.-SPb,1991.P.194-195.

[5] Blummer, M. Polycyclic aromatic compounds in nature. - Scientific American Journal.1976.No.234.P.34-45.

[6] Bogdanovsky G.A. Chemical ecology // G.A. Bogdanovsky. - Moscow: Moscow State University, 1994.-237p.

[7] Yu.V.Novikov. Ecology of the environment and human: Moscow, 2005, p.347.

Citation: E.M.Gadirova, E.G.Azimov, N.Sh.Sharifova, Determination of Water Samples Contaminated with Oil and Oil Product International Journal of Research Studies in Science, Engineering and Technology. 2017;4(5):10-12.

Copyright: (O) 2017 E.M.Gadirova, et al. This is an open-access article distributed under the terms of the Creative Commons Attribution License, which permits unrestricted use, distribution, and reproduction in any medium, provided the original author and source are credited. 